\title{
Environmental risk of pharmaceuticals: let's look at the whole package
}

\author{
Unax Lertxundi ${ }^{1}$, Saioa Domingo-Echaburu ${ }^{1}$, and Gorka Orive ${ }^{1}$ \\ ${ }^{1}$ Affiliation not available
}

November 26, 2021

\begin{abstract}
Concern about potential deleterious effects of pharmaceuticals in the environment is growing fast. From wiping out vulture populations in Asia, to feminization of fish, pharmaceuticals have shown to provoke important consequences albeit at very low concentrations. A recent article addresses the environmental impact of metered-dose inhalers for asthma in the United Kingdom due to the greenhouse effects hydrofluorocarbons they contain. Since 2005, it is mandatory for all new drugs in Europe to be assessed for their environmental impact. Crucially, this regulation solely refers to the active pharmaceutical ingredient, not the "whole medicine" or finished medical product. This can sometimes lead to incongruences. For instance, it does not consider

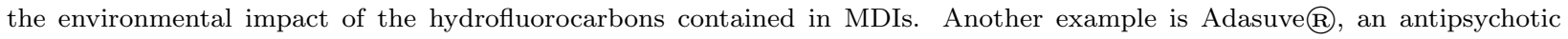
(loxapine) aimed at the rapid control of agitation in patients suffering from psychotic disorders. The device was developed as a rapid systemic delivery of loxapine by inhalation of a thermally generated aerosol for single use. Apart from the active substance it holds a medical-grade plastic housing and a lithium battery. Therefore, after every single use, a lithium battery waste is produced. We envision that we are on a brink of a new era in pharmacotherapy, in which environmental aspects of drugs are taken into account. In definitive, we agree with Wilkinson \& Woodcock. When considering the environmental impact of pharmaceuticals, we need to take into account the whole package.
\end{abstract}

\section{Hosted file}

manuscript_whole package_v3.docx available at https://authorea.com/users/448058/articles/ 546947-environmental-risk-of-pharmaceuticals-let-s-look-at-the-whole-package 